\title{
Evaluation of 3D heads-up vitrectomy: outcomes of psychometric skills testing and surgeon satisfaction
}

\author{
Mario R. Romano ${ }^{1}$ Gilda Cennamo ${ }^{2}$ Chiara Comune ${ }^{2}$ - Michela Cennamo ${ }^{2}$ - Mariantonia Ferrara ${ }^{2}$. \\ Luca Rombetto ${ }^{2} \cdot$ Giovanni Cennamo ${ }^{2}$
}

Received: 6 August 2017 / Revised: 19 October 2017 / Accepted: 30 October 2017 / Published online: 15 February 2018

(c) The Author(s) 2018. This article is published with open access

\begin{abstract}
Objectives To evaluate the use of a three-dimensional heads-up microscope (3DM) during 25-gauge pars plana vitrectomy (PPV) compared with a traditional ophthalmic microscope (TM) in terms of efficacy, safety, and teaching and learning satisfaction.

Methods Prospective comparative interventional study. Fifty eyes affected by one of the following diseases: rhegmatogenous or tractional retinal detachment, epiretinal membrane, full-thickness macular hole, vitreous hemorrhage, or dropped lens. The 50 eyes were randomly assigned to one of two groups: group A ( 25 eyes) underwent 25 -gauge PPV with 3DM, and group B (25 eyes) underwent 25-gauge PPV with TM. The main outcome measures were the duration of the operation, intraoperative complications, and surgeon and observer satisfaction. A questionnaire was used to assess surgeon satisfaction according to the following parameters: comfort, visibility, image quality, depth perception, simplicity of use, maneuverability, and teaching. A questionnaire to assess observer satisfaction was completed by 20 observers (surgical residents or ophthalmic surgeons).

Results The degree of satisfaction was higher using 3DM for both surgeons and observers $(P<0.001)$. The average duration of the operation did not differ significantly between the two methods. No major complications occurred for either method. Conclusions PPV with 3DM is more comfortable for the surgeon and poses no substantially greater risk of complications for the patient. The high-definition screen delivers excellent depth perception and better screen parameter control, which results in high-quality surgical performance. 3DM surgery helps to significantly improve teaching and learning intra-operative surgical procedures.
\end{abstract}

\section{Introduction}

During the past 10 years, despite of the development of new surgical techniques such as small-gauge $(G)$ pars plana vitrectomy (PPV) and intraoperative optical coherence tomography, no major changes have been applied to the use of the surgical microscope in vitreoretinal surgery $[1,2]$.

Mario R. Romano

mario.romano.md@gmail.com

1 Department of Biomedical Science, Humanitas University, Via Manzoni 113, Rozzano, Milano 20089, Italy

2 Dipartimento di Neuroscienze, Scienze Riproduttive ed Odontostomatologiche, University Federico II, Via Pansini 5, Naples 80131, Italy
Novice retinal surgeons are often plagued by the difficulty in obtaining the best operative view, especially for surgery in the posterior segment where the fundus visualization is indirect through the lens [3]. Visualization and perception of depth are critical steps in learning to perform a vitrectomy [1]. In this type of surgery, the surgeon looks through the binoculars of the microscope when performing the operation, and students and other observers watch the procedure on another monitor, which does not have the same imaging resolution as the microscope used by the surgeon. Moreover, the images are two dimensional (2D), and the observers cannot determine the surgical depth. However, even this limits the visualization because the images the assistant sees are dimmer than that seen by the primary surgeon in most TMs.

Three-dimensional (3D) imaging allows to overcome some of the challenges associated with vitreoretinal surgery. With a 3D visualization system, the entire team can see on a 
monitor exactly what the surgeon sees live during the operation. The purpose of this study was to evaluate the use of a 3D heads-up microscope (3DM) during $25 \mathrm{G} \mathrm{PPV}$ and to compare it to TM in terms of efficacy, safety, and satisfaction in teaching and learning.

\section{Materials and methods}

\section{Study design}

A pilot prospective comparative study was designed. Institutional review board approval was obtained and the study was conducted according to the Declaration of Helsinki. The same surgeon performed all operations. All patients were informed about the surgical procedure and signed a written consent form before surgery.

\section{Inclusion and exclusion criteria}

We included patients older than 18 years who were affected by one of the following diseases: rhegmatogenous (RRD); tractional retinal detachment (TRD); epiretinal membrane (ERM); full-thickness macular hole (FTMH); vitreous hemorrhage (VH); silicone oil (SO)-filled eye or dropped lens (DL).

We excluded patients affected by untreated or uncontrolled ocular disease that lead to unacceptable higher risk of intra- and post-operative complications, such as uncontrolled ocular inflammation or infection, untreated ocular malignancy and uncontrolled glaucoma. Patients with uncontrolled severe systemic disease related to significantly higher operative risk were considered ineligible for surgery. We also excluded pregnant women due to the specific risks related to supine position during surgery, operative time, risks of retrobulbar anesthesia, and intraoperative and postoperative drugs [4].

\section{Participants}

This study was performed on a total of 50 eyes of 50 patients who underwent single-surgeon $25 \mathrm{G}$ PPV for vitreoretinal disease between March and July 2015 in the Ophthalmic Clinic of the University of Naples 'Federico II'. The Random Allocation Software generated two groups of patients: group A $(n=25)$ who underwent $25 \mathrm{G}$ PPV with $3 \mathrm{DM}$ and group B $(n=25)$ who underwent $25 \mathrm{G}$ PPV with TM.

\section{Description of the surgical techniques}

All patients underwent surgery under retrobulbar block. The cataract surgery was combined to the vitrectomy using the technique of phacoemulsification in six patients in group A (five affected by ERM and one with SO in the vitreous chamber) and in four patients in group B (three affected by ERM and one with SO-filled eye). The patient with displacement of the crystalline lens associated with RRD underwent a fragmatome lensectomy. Every PPV surgery was performed using the Constellation Vitreoretinal Surgical System and Xenon light sources (both from Alcon Laboratories, Inc. Fort Worth, TX, USA). Wide-angle fundus visualization was achieved using the panoramic RUV800 Viewing System for Retinal Surgery (Leica Microsystems, Schmidheiny-Strasse 201, Switzerland). Microscope frame rate was 60 frame per second (f.p.s.) per camera. The endoillumination was set between 30 and $40 \%$ with gain 2 or 3 using 3DM and between 40 and 50\% using the TM. The iris diaphragm was completely opened for the white-white balance, and then set at $75 \%$ to perform the surgeries.

The surgical procedure varied according to the pathology. A core vitrectomy was performed and a posterior vitreous detachment was induced. The posterior hyaloid membrane and posterior cortical vitreous were dissected from the macula using aspiration and/or manual membrane peeling (for ERM or internal limiting membrane in cases of ERM or FTMH, respectively). Peripheral vitreous shaving was then performed in coordination with scleral indentation in patients with RRD or TRD. The patients with ERM had fluid/air exchange. The patients with MH had fluid/air/gas (C3F8) exchange. The patients with RRD or TRD had air/ fluid exchange, with perfluorocarbon injection, endolaser treatment, or cryotherapy, as necessary. The tamponade injected by the end of surgery was SO in 6/11 and GAS in 5/11 RRD; whereas for TRD SO was used in all 4/4 cases. Vitreous hemorrhage associated with PDR was removed by vitrectomy with laser treatment. The time was estimated and recorded for each operation in minutes for both groups.

\section{Questionnaires}

Two questionnaires were designed to evaluate the satisfaction of the surgeon and observers with the two techniques. The surgeon was asked to rate seven parameters on a scale of 1 to $5: 1=$ low; $2=$ below average; $3=$ average; $4=$ good; and $5=$ excellent. The parameters were comfort, visibility, image quality, depth perception, simplicity of use, maneuverability and teaching. The observers were asked to rate their satisfaction with four items using the same rating scale for visibility, image quality, depth perception, and teaching. At the end of each surgical session, each participant (surgeon and observers) was asked to complete the questionnaire for both types of surgery. 
Table 1 Demographic and clinical findings

\begin{tabular}{|c|c|c|c|}
\hline & $3 \mathrm{D}$ & $\mathrm{TM}$ & $p$-value \\
\hline Male/female, $n$ & $13 / 12$ & $11 / 14$ & 0.571 \\
\hline Age, median [IQR] & $66[63-68]$ & $67[64.5-69]$ & 0.315 \\
\hline Eye right/left, $n$ & $13 / 12$ & $11 / 14$ & 0.571 \\
\hline Phakic/pseudophakic, $n$ & $17 / 8$ & $16 / 9$ & 0.765 \\
\hline $\begin{array}{l}\text { Rhegmatogenous retinal } \\
\text { detachment, } n\end{array}$ & 5 & 6 & 0.733 \\
\hline Tractional retinal detachment, $n$ & 1 & 3 & 0.297 \\
\hline $\begin{array}{l}\text { Droppled lens + retinal } \\
\text { detachment, } n\end{array}$ & 1 & 0 & 0.312 \\
\hline Epiretinal membrane, $n$ & 6 & 5 & 0.733 \\
\hline $\begin{array}{l}\text { Epiretinal membrane and } \\
\text { cataract, } n\end{array}$ & 5 & 3 & 0.440 \\
\hline Full thickness macular hole, $n$ & 4 & 4 & 1 \\
\hline $\begin{array}{l}\text { Silicone oil in vitreous } \\
\text { chamber }+ \text { cataract, } n\end{array}$ & 1 & 1 & 1 \\
\hline $\begin{array}{l}\text { Vitreous hemorrhage in the } \\
\text { setting of proliferative diabetic } \\
\text { retinopathy, } n\end{array}$ & 2 & 3 & 0.637 \\
\hline
\end{tabular}

$I Q R$ interquartile range

\section{Statistical analysis}

We performed the statistical analyses using SPSS Statistics Base version 23.0 (IBM Software). Demographic and clinical data were compared using Pearson's chi-squared test. Mann-Whitney $U$-test was used to compare the continuous variabes (surgeon's and observers' satisfaction parameters for $3 \mathrm{DM}$ and $\mathrm{TM}$ ); the continuous variables were expressed ad median and interquartile range (IQR). Data were considered significant with $P$-value $<0.05$.

\section{Results}

All data on demographic and clinical findings of the patients enrolled are shown in the Table 1. No statistically significant difference has been found regarding sex, age, lens status, and diagnosis between group $\mathrm{A}$ and group B (Table 1).

The occurrence of intraoperative complications after 25 G PPV using the two techniques was evaluated. There was only one incident, in group A, of touching of a crystalline lens during trocar insertion.

The mean operating time was evaluated for each procedure (Table 2). The number of cases for each disease category was too small to assess any statistically significant difference in operating time. However, our data showed a trend of 3DM procedures to take longer than surgeries performed with TM (Table 2).
Table 2 Mean surgery time (s.d.) in min in groups A and B

\begin{tabular}{lcc}
\hline Type of surgery and pathology & \multicolumn{2}{c}{ Surgery time, min (s.d.) } \\
\cline { 2 - 3 } & $\begin{array}{c}\text { Group A } \\
(3 D M)\end{array}$ & $\begin{array}{c}\text { Group B } \\
\text { (TM) }\end{array}$ \\
\hline Vitrectomy for RRD & $40(15)$ & $35(15)$ \\
Vitrectomy for diabetic TRD & 60 & $53(10)$ \\
Vitrectomy + peeling of ERM & $22(6)$ & $20(6)$ \\
Vitrectomy for hemovitreous caused & $46(5)$ & $42(7)$ \\
by PDR & & \\
Vitrectomy for MH & $27(5)$ & $21(8)$ \\
Cataract surgery + vitrectomy + & $44(7)$ & $40(6)$ \\
peeling of ERM & & \\
Cataract surgery + silicon oil removal & 30 & 25 \\
$\begin{array}{l}\text { Droppled lens }+ \text { rhegmatogenous } \\
\text { retinal detachment }\end{array}$ & 48 & \\
\hline
\end{tabular}

ERM epiretinal membrane, $M H$ macular hole, $P D R$ proliferative diabetic retinopathy, $R R D$ rhegmatogenous retinal detachment, $T R D$ tractional retinal detachment

Table 3 Mean scores of surgeon's questionnaire

\begin{tabular}{llll}
\hline & $3 \mathrm{D}$ & $\mathrm{TM}$ & $p$-value \\
\hline Satisfaction, median [IQR] & $30[30-31]$ & $28[26.5-28]$ & 0.000 \\
Comfort & $4[4-5]$ & $3[3-3]$ & 0.000 \\
Visibility & $4[4-5]$ & $5[4-5]$ & 0.075 \\
Image quality & $4[4-4.5]$ & $4[4-4]$ & 0.763 \\
Depth perception & $5[5-5]$ & $4[3.5-4]$ & 0.000 \\
Simplicity to use & $4[4-4]$ & $5[4-5]$ & 0.000 \\
Maneuverability & $4[4-4]$ & $4[4-4]$ & 0.484 \\
Teaching & $5[5-5]$ & $3[2.5-3]$ & 0.000 \\
\hline
\end{tabular}

$I Q R$ interquartile range

Table 4 Mean scores of observers' questionnaire

\begin{tabular}{llll}
\hline & $3 \mathrm{D}$ & $\mathrm{TM}$ & $p$-value \\
\hline Satisfaction, & 18.96 & 10.24 & 0.000 \\
median [IQR $]$ & {$[16.36-19.64]$} & {$[8.3-11.46]$} & \\
Visibility & $4.68[3.91-5]$ & $2.64[2.34-3.34]$ & 0.000 \\
Image quality & $4.68[3.94-5]$ & $2.64[2.32-2.74]$ & 0.000 \\
Depth perception & $4.6[3.93-4.96]$ & $2.15[1.2-2.68]$ & 0.000 \\
Teaching & $4.92[4.73-5]$ & $2.32[1.2-2.64]$ & 0.000 \\
\hline
\end{tabular}

$I Q R$ interquartile range

The surgeon's responses to the questionnaire are shown in Table 3. Using 3DM, the eyepieces were permanently removed after three surgical procedures. Each observer was asked to complete the questionnaire for both the 3DM surgery and TM surgery and the scores are shown in Table 4. The overall satisfaction of the surgeon resulted significantly higher for 3D than TM; no statistically significant difference was found regarding visibility, image 
Fig. 1 Tractional retinal detachment in proliferative diabetic retinopathy. Needs of anaglyphic glasses for 3D effect

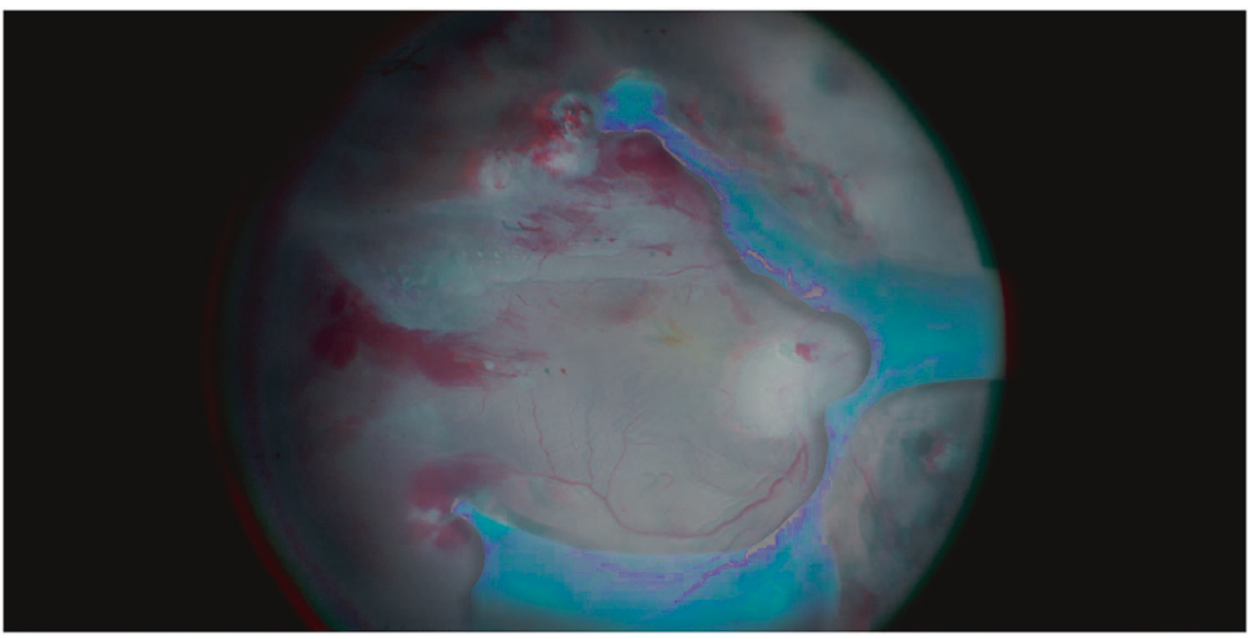

quality, and maneuverability, whereas 3D has been shown significantly better for the remaining items (Table 3). In observers group 3DM had a significantly higher rating of satisfaction than the TM for each parameter, with the best results obtained for depth perception and teaching (Table 4).

\section{Discussion}

In this pilot study, we evaluated intraoperative feedback during the use of the 3D heads-up instrument in vitreoretinal surgery. The 3D software allows the operator to use the $2 \mathrm{D}$ view, to regulate the white balance; to change colors, contrast, brightness, gain, hue, and gamma values; and to record in $2 \mathrm{D}$ and $3 \mathrm{D}$ in different formats. The ability to visualize the surgical field on the camera display with a delay of only $90 \mathrm{~ms}$ allows the surgeon to operate from the screen without looking through the microscope eyepieces [5]. The learning curve seems to be short, since it has been reported that just few surgical procedures are enough to make the surgeon feel comfortable with 3DM [5, 6]. The results of the present study showed that 3DM surgery provides similar performance compared with TM surgery in terms of surgeon's visibility $(P=0.075)$ and image quality $(P=0.763)$, while has significant advantages in terms of the surgeon's comfort and teaching $(P<0.001$ for both).

The first concern for a vitreoretinal surgeon is to maintain a comfortable and stable position that allows to carry out the surgical procedures safely. Because surgical performance can be influenced by the surgeon's comfort, heads-up surgery helps to enhance the procedure's safety. Using TM, the vitreoretinal surgeon cannot move the head, shoulders and back during the operation, and neck and musculoskeletal fatigue, stiffness, mental and physical stress, and eyestrain are commonly reported after surgery [7]. The 3DM procedure is more comfortable because the surgeon can choose the most comfortable surgical position that allows some degree of movement [8, 9]. The use of an external monitor, adjustable in height, improves ergonomics reducing back and neck stress, and pain, which can have a compounding effect over the course of the years. Additionally, the work using heads-up method has been perceived as less strenuous, quicker, and more pleasant compared to the work with TM and this can lead to reduced mental stress using 3DM [6]. It is known that watching 3D images can induce a '3D asthenopia' [10], but the surgeon (MRR) did not experience any symptoms attributable to this condition.

Skinner and Riemann suggested that the heads-up digitally assisted technology could be preferred for patients with positioning challenges, such as in case of significant musculoskeletal limitations [11].

Another important requirement for the performance of vitreoretinal surgery is stereopsis or the perception of depth achieved by analysis of the relative disparity of image elements projected onto the two retinae [12, 13]. (Fig. 1) Stereopsis is mandatory for surgical tasks that require precise hand-eye coordination [14]. In 3DM, the distance between the optical beam paths is $24 \mathrm{~mm}$ instead of the 22 $\mathrm{mm}$ in TM. The surgeon can choose between objective lenses with working distance of $174 \mathrm{~mm}, 200 \mathrm{~mm}$, or 225 $\mathrm{mm}$. This larger stereo basis means greater stereopsis, both in cases of normal use with a binocular tube and in cases of 3D heads-up surgery.

The new microscope makes it possible to reduce the power of the endoillumination of the light pipe to $10 \%$ with no significant decrease of image quality thanks to the variation in brightness and gain. Indeed, the increase of the gain can produce a brighter image and compensate for a decrease of endoillumination to $20 \%$ without visible increased noise [6]. Moreover, Kunikata et al. [15] reported excellent visualization using the Constellation illuminator settled to $1 \%$ during 6 macular surgeries. We set the endoillumination between 30 and $40 \%$ with gain 2 or 3 and 
between 40 and $50 \%$ using the 3DM and the TM, respectevely.

Retinal damage secondary to the use of the endoillumination during vitreoretinal surgery has been well noted and serves as evidence of phototoxicity through different mechanisms including photothermal, photomechanical, and photochemical means [16-19]. In their studies of retinal light toxicity, Noell et al. and Eichenbaum et al supported the concept of a critical threshold dose necessary for injury $[20,21]$. Therefore, reducing the intensity of the light should help decrease the risks of retinal damage secondary to endoillumination and this advantage may be more suitable in patients affected by macular or retinal degenerative diseases due to their increased susceptibility to phototoxicity $[15,22]$.

The 3DM technique provides new and better visualization for the surgeon. Removing the eyepieces, all the light is sent to the camera improving the quality of digital image, whereas using eyepieces $50 \%$ of light is sent to them by the beam splitter [6]. In a recent experimental study, most of volunteers found the 3D images sharper and with equal or higher resolution than TM images, despite the measurement of resolution of TM with eyepieces was higher than 3D system [6]. Moreover, the camera in heads-up surgery works in a higher dynamic range image mode than traditional cameras allowing the human eyes to view the digital images as superior to the TM images [6]. With 3DM system the anterior vitreous and retinal plane can be highlighted modifying the gain and brightness, even when the light is outside the globe used as a scleral depressor [23].

Finally, visualization is a critical step for observers, especially residents and fellows, learning to perform vitrectomy. The 3D high-definition screen delivers excellent depth perception and more minute anatomical details, which will help improve understanding and knowledge retention. Indeed, all the observes can have the same experience of depth perception perceived by the first surgeon and there is no need of the observer's binoculars. The engagement of the entire team visually in the procedure can facilitate communication and support the surgical workflow and the educational environment, improving teaching during the live surgical procedure. Moreover, the assistant images are dimmer than the primary surgeon images in most TMs because they are provided with two beam paths that lead to a necessary light loss for both the primary and the assistant surgeon. However, the newest TMs are equipped with four separate beam paths in the same zoom system to overcome this limit. Our results were consistent with the above mentioned advantages of 3DM, as well as the observers' questionnaire results showed that the most satisfying items were related to depth perception and teaching.

The heads-up surgery with 3DM has also been shown to be safe. Higher closure rate of $\mathrm{MH}$ using 3DM has been reported by Eckardt and Paulo compared to their previous results using TM [11]. No additional or more frequent complications have been related to the use of 3DM in both anterior and posterior segment surgeries [6, 24]. We registered only one incident of inadvertent lens touch during trocar insertion, in group A. No major complications occurred in both groups. The small sample size does not allow to evaluate if the incidence of the event is significantly related to the microscope used. However, our surgeon felt comfortable performing the surgical external steps with $3 \mathrm{DM}$ and did not attribute this complication to $3 \mathrm{D}$ vision.

In our study surgeries performed using 3DM took longer than ones with TM. All procedures were carried out by an experienced surgeon (MRR), who tried the 3DM for the first time. Therefore, the operative timing trend could be imputed to the 'learning factor'. The surgeon became quickly proficient in using 3DM, without any additional difficulties in both anterior and posterior surgery. Moreover, Eckardt et al. suggested that longer operation time could be caused by the need of more frequent focusing at the higher magnification used to improve the resolution of 3DM images [11].

There are few reports in literature about the use of $3 \mathrm{D}$ microscope, especially in vitreoretinal surgery $[6,15]$. This is the first prospective study that compare the use of traditional and 3D microscope in terms of satisfaction not only for the surgeon, but also for the observers. However, this is a pilot study and the sample size is a limitation. Further prospective studies with a larger number of patients are needed to confirm our preliminary results.

In conclusion, 3DM shows good surgical performance compared with standard microscope imaging, allowing some advantages over TM without significant additional risks of complications. We believe this report is significant because it is the first demonstration of an improvement in imaging parameters that can influence the outcome of ophthalmic surgery. Moreover, the significant advantage in terms of teaching represents a pivotal point for the improvement of the training of new surgeons, especially during residency and vitreoretinal fellowships training.

\section{Summary}

\section{What was known before}

- With the use of a traditional microscope (TM), only the assistant, who looks through the binoculars on the side, can learn how to perform the operation.

- Moreover the images the assistant sees are not at the same resolution as that seen by the primary surgeon in most TMs. 


\section{What this study adds}

- The 3D microscope delivers excellent depth perception and better screen parameter control, which results in high-quality surgical performance.

- 3DM surgery helps to significantly improve teaching and learning intra-operative surgical procedures.

\section{Compliance with ethical standards}

Conflict of interest The authors declare that they have no competing interests.

Open Access This article is licensed under a Creative Commons Attribution-NonCommercial-NoDerivatives 4.0 International License, which permits any non-commercial use, sharing, distribution and reproduction in any medium or format, as long as you give appropriate credit to the original author(s) and the source, and provide a link to the Creative Commons license. You do not have permission under this license to share adapted material derived from this article or parts of it. The images or other third party material in this article are included in the article's Creative Commons license, unless indicated otherwise in a credit line to the material. If material is not included in the article's Creative Commons license and your intended use is not permitted by statutory regulation or exceeds the permitted use, you will need to obtain permission directly from the copyright holder. To view a copy of this license, visit http://creativecommons.org/licenses/by-nc-nd/4.0/.

\section{References}

1. Cionni RJ, Pei R, Dimalanta R, Lubeck D. Evaluating red reflex and surgeon preference between nearly-collimated and focused beam microscope illumination systems. Transl Vis Sci Technol. 2015;4:7.

2. Du LT, Wessels IF, Underdahl JP, Auran J. Stereoacuity and depth perception decrease with increased instrument magnification: comparing a non-magnified system with lens loupes and a surgical microscope. Binocul Vis Strabismus Q. 2001;16:61-7.

3. Bansal AS, London N, Witkin A. Surgical pearls for the beginning vitreoretinal fellow. Retina Today I. 2011;6:26-30.

4. Cheek TG, Baird E. Anesthesia for nonobstetric surgery: maternal and fetal considerations. Clin Obstet Gynecol. 2009;52:535-45.

5. Figueroa MS. 3D vitrectomy. Is it really useful? Arch Soc Esp Oftalmol. 2017;92:249-50.

6. Eckardt C, Pauo EB. Heads-up surgery for vitreoretinal procedures: an Experimental and Clinical Study. Retina. 2016;36:137-47.
7. Kelts GI, McMains KC, Chen PG, Weitzel EK. Monitor height ergonomics: a comparison of operating room video display terminals. Allergy Rhinol (Provid). 2015;6:28-32.

8. Liang B, Qi L, Yang J, Cao Z, Zu X, Liu L, et al. Ergonomic status of laparoscopic urologic surgery: survey results from 241 urologic surgeons in China. PLoS ONE. 2013;8:e70423.

9. Welcker K, Kesieme EB, Internullo E, Kranenburg van Koppen LJ. Ergonomics in thoracoscopic surgery: results of a survey among thoracic surgeons. Interact Cardiovasc Thorac Surg. 2012;15:197-200.

10. Kim SH, Suh YW, Song JS, Park JH, Kim YY, Huh K, et al. Clinical research on the ophthalmic factors affecting $3 \mathrm{D}$ asthenopia. J Pediatr Ophthalmol Strabismus. 2012;49:248-53.

11. Skinner CC, Riemann CD. "Heads up" digitally assisted surgical viewing for retinal detachment repair in a patient with severe kyphosis. Retina Cases Brief Rep. 2016:1-3.

12. Barlow HB, Blakemore C, Pettigrew JD. The neural mechanism of binocular depth discrimination. J Physiol. 1967;193:327-42.

13. Westheimer G. Seeing depth with two eyes: stereopsis. Proc Biol Sci. 1994;257:205-14.

14. Bloch E, Uddin N, Gannon L, Rantell K, Jain S. The effects of absence of stereopsis on performance of a simulated surgical task in two-dimensional and three-dimensional viewing conditions. $\mathrm{Br}$ J Ophthalmol. 2015;99:240-5.

15. Kunikata H, Abe T, Nakazawa T. Heads-up Macular Surgery with a 27-Gauge Microincision Vitrectomy System and Minimal Illumination. Case Rep Ophthalmol. 2016;7:265-9.

16. Glickman RD. Phototoxicity to the retina: mechanisms of damage. Int J Toxicol. 2002;21:473-90.

17. Solley WA, Sternberg P Jr. Retinal phototoxicity. Int Ophthalmol Clin. 1999;39:1-12.

18. Verma L, Venkatesh P, Tewari HK. Phototoxic retinopathy. Ophthalmol Clin North Am. 2001;14:601-9.

19. Wu J, Seregard S, Algvere PV. Photochemical damage of the retina. Surv Ophthalmol. 2006;51:461-81.

20. Noell WK, Walker VS, Kang BS, Berman S. Retinal damage by light in rats. Invest Ophthalmol. 1966;5:450-73.

21. Eichenbaum JW, Cinaroglu A, Eichenbaum KD, Sadler KC. A zebrafish retinal graded photochemical stress model. J Pharmacol Toxicol Methods. 2009;59:121-7.

22. Youssef PN, Sheibani N, Albert DM. Retinal light toxicity. Eye (Lond). 2011;25:1-14.

23. Mandelcorn ED, Manusow JS, Parke DW III, Albini TA. Unassisted scleral depression during vitrectomy surgery: two simple, cost-effective techniques. Ophthalmic Surg Lasers Imaging Retin. 2015;46:577-8.

24. Weinstock RJ First clinical use of on-screen 3-D image templates during small-incision cataract surgery. Paper presented at the American Society of Cataract and Refractive Surgery Annual meeting: 12 April 2010, Boston, MA, USA. 